Applied Psycholinguistics 23 (2002), 567-598

Printed in the United States of America

DOI: 10.1017.S0142716402004046

\title{
Assessing bilingual dominance
}

\author{
JAMES EMIL FLEGE \\ University of Alabama at Birmingham
}

IAN R. A. MACKAY

University of Ottawa

THORSTEN PISKE

Kiel University

ADDRESS FOR CORRESPONDENCE

J. E. Flege, Division of Speech and Hearing Sciences, University of Alabama at Birmingham,

CH20, Room 119, 1530 Third Avenue, South, Birmingham, AL 35294-2042.

\begin{abstract}
This study used two methods to assess bilingual dominance in four groups of 18 Italian-English bilinguals, who were selected on the basis of age of arrival (AOA) in Canada (early: 2-13 years; late: 15-26 years) and percentage use of the first language (L1), Italian (low L1 use: 1-15\%; high L1 use: $25-85 \%$ ). Ratios were derived from the bilinguals' self-ratings of ability to speak and understand Italian compared to English (the "verbal" self-rating ratios) and to read and write Italian compared to English (the "written" self-rating ratios). The ratio of the mean duration of English and Italian sentences produced by each bilingual was also computed. AOA and L1 use had the same effect on the self-rating and sentence duration ratios, which were correlated. The bilinguals who arrived in Canada as young adults and continued to use Italian often were the most likely to be Italian dominant. Dominance in Italian was associated with a relatively high level of performance in Italian (assessed in a translation task) and relatively poor performance in English (assessed by measuring strength of foreign accents). Both groups of late bilinguals (late low, late high) and both groups of early bilinguals (early low, early high) were found to produce English sentences with detectable accents. However, a group of 18 bilinguals (all early bilinguals) selected from the original sample of 72 based on their dominance in English did not have detectable foreign accents. This suggested that interlingual interference effects may not be inevitable.
\end{abstract}

It is common to classify bilinguals as dominant in the first language (L1), dominant in their second language (L2), or balanced (i.e., dominant in neither the L1 nor the L2). A balanced bilingual may be defined as one "who does equally well in both languages" on a variety of tests (Grosjean, 1982, p. 234) or who shows "little interlingual interference" (Lambert, 1990, p. 203). The comparison of homogenous groups of balanced bilinguals differing in age of L2 learning might, therefore, provide a way to choose between two well-known explanations for differences in L2 performance between bilinguals and monolingual native speakers of the L2: the passing of a maturationally defined critical period (e.g., 
Flege et al.: Assessing bilingual dominance

DeKeyser, 2000) and interlingual interference (e.g., Bialystok \& Miller, 1998). If balanced bilinguals do not show interlingual interference, then differences that are observed between monolinguals and balanced bilinguals who began learning their L2 in adulthood might be attributed to the passing of a critical period for L2. However, before such tests can be performed, better methods for selecting participants for bilingual research (as dominant in one of their two languages or balanced) are needed, as well as better methods for matching participants according to bilingual dominance. That was the aim of this methodological study.

Grosjean (1998, p. 134) noted that diverse techniques have been used to select participants for bilingual research and that, in some studies, insufficient information regarding bilingual participants has been provided. The lack of sufficient information regarding participants, according to Grosjean, has impeded the replication of previous findings and hindered cross-study comparisons of results. For example, different predictions might be generated if the groups of bilinguals being compared are dominant in the same or different languages (Talamas, Kroll, \& Dufour, 1999) or if the groups being compared all consist of balanced bilinguals (Peal \& Lambert, 1962).

The importance of participant selection can be illustrated by considering the frequently cited study of Cutler, Mehler, Norris, and Segui $(1989,1992)$. The aim of this study was to learn if bilingual speakers of French and English would show the speech segmentation patterns previously observed for French and English monolinguals when processing French and English speech materials, respectively. The participants had all been exposed to both of their languages from early childhood, used both languages regularly, and were accepted by French and English monolinguals as native speakers of their two languages. When the segmentation pattern obtained for the bilinguals failed to resemble those obtained previously for either French or English monolinguals, the bilingual participants were reassigned to subgroups based on their response to a single question ("If you had to lose one of your languages to save your life, which would you keep?"). The participants classified as French dominant (i.e., those who would keep French) but not those classified as English dominant (those who would keep English) were then found to segment French materials like French monolinguals. Also, the French-dominant bilinguals, unlike the English-dominant bilinguals, showed different language-appropriate strategies when processing the French and English materials.

Cutler et al. (1989) concluded that bilingual dominance exerts an important influence on syllable segmentation. However, Grosjean (1998, p. 134) criticized the technique used by Cutler et al. (1989) to classify bilinguals as French dominant or English dominant for two reasons. First, all of the Cutler et al. participants were determined to have been balanced bilinguals when they were selected for the study. Second, little additional information about the bilinguals was provided. Grosjean also cited a study (Kearns, 1994) that failed to replicate the Cutler et al. findings for bilinguals whose dominance was established using the "Which language would you keep?" question (see also Golato, 1998).

The controversy regarding how best to interpret the findings obtained by Cutler et al. (1989) raises two general participant selection issues. The first is how 
to determine bilingual dominance. At present, there does not appear to be a generally accepted procedure for doing so. Many different procedures have been used to assess bilingual dominance, including self-ratings of ability to read, write, speak, and understand the L1 and L2 (Goggin, Estrada, \& Villarreal, 1994; Kohnert, Hernandez, \& Bates, 1999; Lemmon \& Goggin, 1989; Mägiste, 1979; Talamas et al., 1999); global ratings of fluency (Tamamaki, 1993); the subjective judgment of a bilingual experimenter (Talamas et al., 1999); the scores obtained on vocabulary tests administered in the L1 and L2 (Cromdal, 1999); language history (Chincotta \& Underwood, 1999; Hazan \& Boulakia, 1993); and the ability to make word order judgments in the L1 and L2 (Lemmon \& Goggin, 1989). Other procedures used to determine bilingual dominance have involved measures of what might be called "speed," "fluency," or "automaticity." Researchers have measured the time that bilinguals needed to carry out commands in the L1 and L2 as rapidly as possible (Lambert, 1955), name pictures of familiar L1 and L2 words and digits as rapidly as possible (Mägiste, 1992), and read L1 and L2 texts as rapidly as possible (Favreau \& Segalowitz, 1982, 1983; Macnamara, 1969).

As might be expected, the results yielded by different techniques have sometimes failed to converge. For example, Chincotta and Underwood (1999) examined groups of bilingual children attending a Swedish-medium school in Finland. One group, which was described as balanced bilingual, spoke Finnish at home. Another group, described as Swedish dominant, spoke Swedish at home but were said to have nativelike fluency in Finnish because they used Finnish frequently when not at home or school. A dependent variable examined in one experiment was the time needed to say three-syllable Finnish and Swedish words as rapidly as possible. This testing procedure resembled the method used in other studies to classify bilinguals (e.g., Favreau \& Segalowitz, 1982, 1983; Mägiste, 1992), where the language exhibiting the greater speed or faster processing was said to be the "dominant" one (see also Dornic, 1979). However, contrary to what might have been expected from how the bilinguals were classified, the balanced bilinguals produced shorter Finnish than Swedish words whereas the Swedish-dominant bilinguals' Finnish and Swedish words did not differ significantly in duration.

The foregoing example raises the issue of how to select from among the procedures now in use for determining bilingual dominance. According to Lambert, Havelka, and Gardner (1959), an appropriate measure of bilingual dominance will reflect bilinguals' performance on a wide range of L1 and L2 tasks. The method used by Macnamara (1969) seemed to fulfill this requirement. Macnamara administered a battery of tests in two languages to bilingual sixth graders in Montreal and also measured how rapidly these bilinguals could read French and English passages. A faster reading rate in one of the two languages was said to indicate dominance in that language. The reading speed measure proved to be the best predictor, of several measures that were considered, of skill in reading, writing, speaking, and understanding French and English.

Favreau and Segalowitz $(1982,1983)$ used a similar technique to assess dominance in bilingual adults. Roughly half of the bilinguals read a text in one of their two languages (French or English) more rapidly than a text in their other 
language, and so were said to be dominant in the faster language. The L1dominant bilinguals (i.e., those who read the L1 faster than the L2) were found to have stronger foreign accents in the L2 than the balanced bilinguals (i.e., those who read the L1 and L2 at similar rates). The bilinguals' reading rates corresponded to the presentation rates that the bilinguals selected as optimal for comprehending aurally presented passages, suggesting that the observed differences in reading rates were not simply the result of differences in articulatory motor skills. These results supported the view (Lambert, 1990) that balanced bilinguals will show little interlingual interference.

The second general issue pertaining to the selection of participants for bilingual research is how, and to what extent, bilingual dominance may coincide with variation in other variables used to select bilingual research participants. These other variables include language history (e.g., the contexts and ages at which the two languages were acquired), function (e.g., the purposes for which the L1 and L2 are used), and use (the frequency with which the two languages are used, and with whom). The relation between the age of learning the L2 and bilingual dominance is of special interest given the evidence that early and late bilinguals differ in terms of their sensitivity to and processing of grammatical properties of the L2 (e.g., Flege, Yeni-Komshian, \& Liu, 1999; Guillelmon \& Grosjean, 2001; Liu, Bates, \& Li, 1992), overall degree of foreign accent in the L2 (Flege, Munro, \& MacKay, 1995b), overall duration of fluently produced L2 sentences (Guion, Flege, Liu, \& Yeni-Komshian, 2000), production and perception of L2 phonetic segments (e.g., Flege, MacKay, \& Meador, 1999; Flege, Munro, \& MacKay, 1995a; Flege, Schmidt, \& Wharton, 1996; MacKay, Meador, \& Flege, 2001; Munro, Flege, \& MacKay, 1996), and recognition of L2 words in noise (Meador, Flege, \& MacKay, 2000).

One possibility that should be considered, at least for experienced bilinguals who learned their L2 upon immigrating to an L2-speaking country, is that the early versus late distinction is roughly equivalent to the distinction between L2 dominance and L1 dominance. Hazan and Boulakia (1993, p. 22) classified bilinguals as dominant in one of their languages if, based on responses to questionnaire items pertaining to language use, it was designated "the language of greatest exposure in early years." However, Grosjean (1982, p. 244) questioned the view that bilinguals who acquire their L2 in early childhood "produce, perceive, or store it any differently than those who learn it as adolescents or as adults." Grosjean (1982, p. 231) pointed to the importance of "psychosocial factors that surround language acquisition," as well as to factors such as "the regular use of two languages, their domains of use, and the bilingual's need to have certain skills (reading and writing, for instance) in one language but not in the other." In support of this, recent longitudinal and cross-sectional research examining Chinese immigrants in the United States (Jia \& Aaronson, 1999) suggested that Chinese children but not adolescents or adults may become dominant in English. This is because children are typically exposed to and use English more often than older immigrants and they may, over time, use their L1 less frequently than older bilinguals do (see Flege et al. 1995b; Grenier, 1984). Other recent research has suggested that amount of L1 use affects performance 
Flege et al.: Assessing bilingual dominance

in an L2 independently of the age at which L2 learning began (e.g., MacKay, Meador, \& Flege, 2001; Meador, et al., 2000; Piske, MacKay, \& Flege, 2001; Piske, Flege, MacKay, \& Meador, 2002).

\section{THE PRESENT STUDY}

The present study examined 72 Italian-English bilinguals with an average age of 49 years who had lived in Canada for an average of 36 years after immigrating there from Italy. Half of the native Italian participants were early bilinguals whose ages of arrival (AOAs) in Canada ranged from 2 to 13 years; the remaining half were late bilinguals whose AOAs ranged from 15 to 26 years. The early and late bilinguals were subdivided according to amount of self-reported Italian use (low L1 use: 1-15\%; high L1 use: $25-85 \%$ ). This yielded four groups of 18 each.

Bilingual dominance was assessed in two sections. One section presents the bilinguals' self-ratings of ability to read, write, speak, and understand Italian and English. The bilinguals were classified as L1 dominant, balanced, or L2 dominant, depending on whether they gave themselves higher ratings in one of their two languages. In addition to discrete classifications of bilingual dominance, self-rating dominance ratios were also derived from the ratings. The next section presents the duration of matched pairs of English and Italian sentences that the bilinguals repeated following an aural model. Ratios of the average duration of the English compared to Italian sentences provided an objective estimate of bilingual dominance.

The following research questions were asked with respect to the measures of bilingual dominance just described:

1. How does AOA influence bilingual dominance? Will the late bilinguals be L1 dominant and the early bilinguals, L2 dominant?

2. How will amount of continued L1 use influence bilingual dominance? Will bilinguals who use their L1 often be $\mathrm{L} 1$ dominant and those who use their L1 seldom, L2 dominant?

3. Will AOA and L1 use have the same effect on the subjective measure of bilingual dominance (the self-rating ratios) and the objective measure of bilingual dominance (the sentence duration ratios)?

Bahrick, Hall, Goggin, Bahrick, and Berger (1994) used matched performance tests in the L1 and L2 to assess bilingual dominance. Although this seems to us to confuse the explicandum of bilingual research with the explicans, a measure of bilingual dominance can only be validated by demonstrating its ability to predict performance in the L1 and L2 (Lambert et al., 1959). One would expect better L2 performance by L2-dominant than L1-dominant bilinguals, and vice versa; and one would expect better L2 than L1 performance by L2-dominant bilinguals, and vice versa. In the following two sections, therefore, the relation between the dominance measures described earlier and measures of performance in the L1 and L2 was examined. The L2 performance was evaluated by examin- 
ing the degree of overall foreign accent in English sentences produced by the Italian-English bilinguals. The L1 performance was assessed by determining how well they could translate English sentences into Italian.

The measures of bilingual dominance were found to account for a significant amount of variance in both L1 and L2 performance, but they were correlated with other variables commonly used to select participants for L2 acquisition research (viz., AOA, percentage L1 use, and length of residence (LOR) in a primarily L2-speaking country). The primary aim of the regression analyses presented in the next section, therefore, was to determine how much variance in L1 and L2 performance could be accounted for by the bilingual dominance ratios compared to AOA, L1 use, and LOR. The final aim of the study was to compare the L1 and L2 performance of bilinguals, each of whom was reassigned to one of three groups of 18 each, based on bilingual dominance.

\section{GENERAL METHOD}

\section{Procedure}

Ninety adults were tested individually in a small, quiet room located in a Roman Catholic church in Ottawa, Canada. As described later, 72 of the participants were Italian-English bilinguals and 18 were native speakers of Canadian English who were not proficient in any language other than English.

All 90 participants were tested in English by a native English-speaking experimenter. The bilingual participants were told when recruited that the research dealt with bilingualism. They were informed more specifically of the nature of the research at the beginning of the test session, as required by informed consent procedures. Among other things, they were told that they would be asked to repeat English and Italian sentences and would be asked to translate English sentences into Italian. This meant that the bilingual subjects were likely to have been in a "bilingual" language mode (Grosjean, 1998).

After passing a pure-tone hearing screening at octave frequencies between 500 and $4000 \mathrm{~Hz}$ (re: $35 \mathrm{~dB} \mathrm{HL}$ ), each participant responded to a language background questionnaire (LBQ) written in English. The LBQ included questions of an objective nature, such as the dates of birth and arrival in Canada (from which the bilinguals' AOAs were calculated) and years of formal education in Italy and Canada. The bilingual participants were asked to estimate their overall percentage use of Italian, as well as their use of Italian in specific contexts, and to identify as many specific people as possible with whom they spoke Italian. Finally, the bilinguals were asked to rate their ability to speak, understand, read, and write English and Italian.

Following completion of the LBQ, a delayed repetition technique was used to elicit production of English sentences by the 90 participants. These sentences were later rated for degree of foreign accent in a study by Piske et al. (2001). The foreign accent ratings were used in this study as a measure of L2 performance. The bilingual participants then repeated matched English and Italian sentences that were aurally presented in alternation. (The native English participants repeated only the English sentences.) The bilinguals' sentences were later 
Applied Psycholinguistics 23:4

Flege et al.: Assessing bilingual dominance

Table 1. Mean characteristics of the four groups of Italian-English bilinguals

\begin{tabular}{lccccccc}
\hline \hline & $N$ & Age & AOA & L1 use & LOR & NII & EDUC \\
\hline Early low & \multirow{2}{*}{18} & 50 & 7 & $7 \%$ & 42 & 2.8 & 14 \\
& & $(4)$ & $(3)$ & $(4)$ & $(4)$ & $(1.4)$ & $(3)$ \\
Early high & \multirow{2}{*}{18} & 49 & 8 & $43 \%$ & 40 & 5.0 & 11 \\
& & $(6)$ & $(4)$ & $(15)$ & $(4)$ & $(1.7)$ & $(6)$ \\
Late low & \multirow{2}{*}{18} & 51 & 20 & $10 \%$ & 31 & 2.6 & 2 \\
& & $(7)$ & $(3)$ & $(5)$ & $(8)$ & $(1.0)$ & $(2)$ \\
Late high & \multirow{2}{*}{18} & 49 & 20 & $53 \%$ & 29 & 4.4 & 2 \\
& & $(8)$ & $(3)$ & $(13)$ & $(9)$ & $(1.6)$ & $(2)$ \\
\hline \hline
\end{tabular}

Note: Age, chronological age (years); AOA, age of arrival in Canada (years); L1 use, self-reported percentage of use of Italian; LOR, length of residence in Canada (years); NII, number of interlocutors in Italian; EDUC, years of education in Canada. Standard deviations are in parentheses.

measured for duration; these measurements are presented below as an index of bilingual dominance. The bilingual participants were later asked to translate aurally presented English sentences into Italian. Native Italian speakers' ratings of the adequacy of the translations will be presented below as a measure of the bilinguals' L1 performance.'

\section{Participants}

All 72 of the Italian-English bilinguals learned English as an L2 upon immigrating to Canada from Italy. The bilingual participants were assigned to one of four groups of 18 each (roughly half female) based on AOA and percentage use of Italian. As shown in Table 1, the mean age of participants in the native English group and in the four groups of bilinguals, who were designated early low, early high, late low, and late high, differed little. (The mean age overall was 49 years.) None of the 90 participants reported a history of auditory disorder.

Characteristics of the bilingual participants were examined in a series of 2 $(\mathrm{AOA}) \times 2$ (L1 use) analyses of variance (ANOVAs). One analysis indicated that, as intended by the design, the early bilinguals had arrived in Canada at an earlier age (AOA) than the late bilinguals had, $F(1,68)=227.3, p<.01$, whereas the AOAs of the low L1 use and high L1 use bilinguals did not differ significantly, $F(1,68)=0.7, p>.10$. The early bilinguals were found to have received more education in Canada than the late bilinguals, $F(1,68)=168.9$, $p<.01$, whereas the low L1 use and high L1 use participants did not differ in terms of years of education in Canada, $F(1,68)=2.2, p>.10$. The early bilinguals had also lived longer in Canada than the late bilinguals, $F(1,68)=47.5$, $p<.01$; however, the low L1 use and the high L1 use participants did not differ significantly in LOR, $F(1,68)=1.4, p>10{ }^{2}$

One criterion used in selecting participants was their percentage use of Italian. Prospective bilingual participants were asked to give an overall estimate of Ital- 
ian use during the screening process. Later, as part of the LBQ, participants were asked to estimate their percentage use of Italian during the preceding 5 years, 5 months, and 5 weeks. The three estimates were highly correlated $(p<$ $.01)$, so an average was calculated. These average estimates, which are presented in Table 1, were also found to be highly correlated, $r(70)=.91, p<.01$, with an average of the bilinguals' reports of their use of Italian in specific contexts (at home, at work, at social events, while shopping, on the telephone, with friends, and with family members). The self-reports of percentage Italian use were validated by asking the bilinguals to identify specific persons with whom they used Italian. The high L1 use participants were able to name more specific people than the low L1 use participants, $F(1,68)=34.1, p<.01$, whereas the number of interlocutors named by the early and late bilinguals did not differ significantly, $F(1,68)=.3, p>.10$.

\section{BILINGUAL DOMINANCE BASED ON SELF-RATED L1 AND L2 PROFICIENCY}

Measures of bilingual dominance derived from the Italian-English bilinguals' self-ratings of L1 and L2 proficiency will be presented in this section. Two measures of dominance were obtained. One dealt with the ability to speak and understand, which is referred to here as verbal ability. The other dealt with the ability to read and write, which is referred to here as written ability. Both discrete and continuous measures of bilingual dominance were obtained. The discrete measures were obtained by classifying bilinguals as Italian dominant or English dominant if they rated their ability to be greater in one language than the other. Continuous measures of bilingual dominance were obtained by calculating ratios based on self-rated abilities in Italian compared to English. Nonparametric and parametric tests were then carried out to determine if bilingual dominance was affected by the bilinguals' age of learning English (as indexed by AOA) and L1 use (as indexed by self-reported percentage use of Italian).

\section{Method}

The bilinguals used equal-appearing interval scales ranging from 1 (poor) to 7 (good) to estimate their ability to speak, understand, read and write their two languages. They used the same scale, in alternation, to estimate their proficiency in English and Italian.

\section{Results and discussion}

The mean self-ratings obtained for the four groups of bilinguals are presented in Table 2. Early bilinguals in the early low and early high groups reported being better able to speak, understand, read, and write English than Italian, whereas the opposite held true for late bilinguals in the late low and late high groups.

Discrete classifications of bilingual dominance derived from the self-ratings of language proficiency are shown in Table 3. Any bilingual whose self-ratings 
Flege et al.: Assessing bilingual dominance

Table 2. Mean self-ratings of ability in English and Italian obtained for four groups of bilinguals

\begin{tabular}{|c|c|c|c|c|c|c|c|c|}
\hline & \multicolumn{2}{|c|}{ Speak } & \multicolumn{2}{|c|}{ Understand } & \multicolumn{2}{|c|}{ Write } & \multicolumn{2}{|c|}{ Read } \\
\hline & E & I & $\mathrm{E}$ & I & $\mathrm{E}$ & I & $\mathrm{E}$ & I \\
\hline Early low & $\begin{array}{c}6.6 \\
(0.6)\end{array}$ & $\begin{array}{c}4.4 \\
(1.2)\end{array}$ & $\begin{array}{c}6.8 \\
(0.4)\end{array}$ & $\begin{array}{c}5.2 \\
(1.4)\end{array}$ & $\begin{array}{c}6.7 \\
(0.6)\end{array}$ & $\begin{array}{c}3.4 \\
(1.4)\end{array}$ & $\begin{array}{c}6.8 \\
(0.4)\end{array}$ & $\begin{array}{c}4.4 \\
(1.8)\end{array}$ \\
\hline Early high & $\begin{array}{c}6.4 \\
(0.9)\end{array}$ & $\begin{array}{c}5.2 \\
(0.9)\end{array}$ & $\begin{array}{c}6.7 \\
(0.7)\end{array}$ & $\begin{array}{c}5.6 \\
(0.9)\end{array}$ & $\begin{array}{c}6.3 \\
(1.0)\end{array}$ & $\begin{array}{c}4.0 \\
(1.6)\end{array}$ & $\begin{array}{c}6.6 \\
(0.8)\end{array}$ & $\begin{array}{c}4.7 \\
(1.5)\end{array}$ \\
\hline Late low & $\begin{array}{c}5.4 \\
(0.6)\end{array}$ & $\begin{array}{c}6.4 \\
(0.8)\end{array}$ & $\begin{array}{c}6.1 \\
(0.8)\end{array}$ & $\begin{array}{c}6.6 \\
(0.6)\end{array}$ & $\begin{array}{c}4.8 \\
(1.5)\end{array}$ & $\begin{array}{c}6.2 \\
(1.0)\end{array}$ & $\begin{array}{c}5.9 \\
(1.0)\end{array}$ & $\begin{array}{c}6.6 \\
(0.9)\end{array}$ \\
\hline Late high & $\begin{array}{c}4.9 \\
(0.7)\end{array}$ & $\begin{array}{c}6.5 \\
(0.7)\end{array}$ & $\begin{array}{c}6.1 \\
(0.9)\end{array}$ & $\begin{array}{c}6.8 \\
(0.4)\end{array}$ & $\begin{array}{c}3.3 \\
(1.9)\end{array}$ & $\begin{array}{c}6.4 \\
(1.0)\end{array}$ & $\begin{array}{c}5.3 \\
(1.4)\end{array}$ & $\begin{array}{c}6.7 \\
(0.6)\end{array}$ \\
\hline$M$ & $\begin{array}{c}5.9 \\
(1.0)\end{array}$ & $\begin{array}{c}5.6 \\
(1.3)\end{array}$ & $\begin{array}{c}6.4 \\
(0.8)\end{array}$ & $\begin{array}{c}6.1 \\
(1.1)\end{array}$ & $\begin{array}{c}5.3 \\
(1.9)\end{array}$ & $\begin{array}{c}5.0 \\
(1.8)\end{array}$ & $\begin{array}{c}6.2 \\
(1.2)\end{array}$ & $\begin{array}{c}5.6 \\
(1.6)\end{array}$ \\
\hline
\end{tabular}

Note: E, English; I, Italian. The rating scales ranged from poor (1) to good (7). Standard deviations are in parentheses.

Table 3. Number of bilinguals classified as dominant in the L1 (Italian), balanced, or dominant in the L2 (English)

\begin{tabular}{lcccccccc}
\hline \hline & \multicolumn{2}{c}{ Speaking and understanding } & & \multicolumn{2}{c}{ Reading and writing } \\
\cline { 2 - 3 } & $\begin{array}{c}\text { English } \\
\text { dominant }\end{array}$ & Balanced & $\begin{array}{c}\text { Italian } \\
\text { dominant }\end{array}$ & & $\begin{array}{c}\text { English } \\
\text { dominant }\end{array}$ & Balanced & $\begin{array}{c}\text { Italian } \\
\text { dominant }\end{array}$ \\
\hline Early low & 17 & 1 & 0 & & 18 & 0 & 0 \\
Early high & 14 & 3 & 1 & & 15 & 2 & 1 \\
Late low & 3 & 2 & 13 & & 2 & 3 & 13 \\
Late high & 0 & 0 & 18 & & 0 & 1 & 17 \\
\hline \hline
\end{tabular}

Note: English dominance, ratios $<1.0$; balanced, ratios $=1.0$; Italian dominant, ratios $>1.0$.

of ability to speak and understand were higher on average for English than Italian was classified as verbally dominant in English. Conversely, any bilingual whose average self-ratings of ability to speak and understand were lower on average for English than Italian was classified as verbally dominant in Italian. (Those few bilinguals with the same average self-ratings in both languages were classified as balanced.) The same procedures were used to classify each bilingual as English dominant, Italian dominant, or balanced in terms of ability to read and write.

Chi-square tests revealed that AOA but not L1 use exerted a significant effect on the discrete dominance classifications. More early than late bilinguals ( 31 vs. 3) were classified as verbally dominant in English $\chi(1)=23.0, p<.01$; conversely, fewer early than late bilinguals ( 1 vs. 31$)$ were classified as verbally 


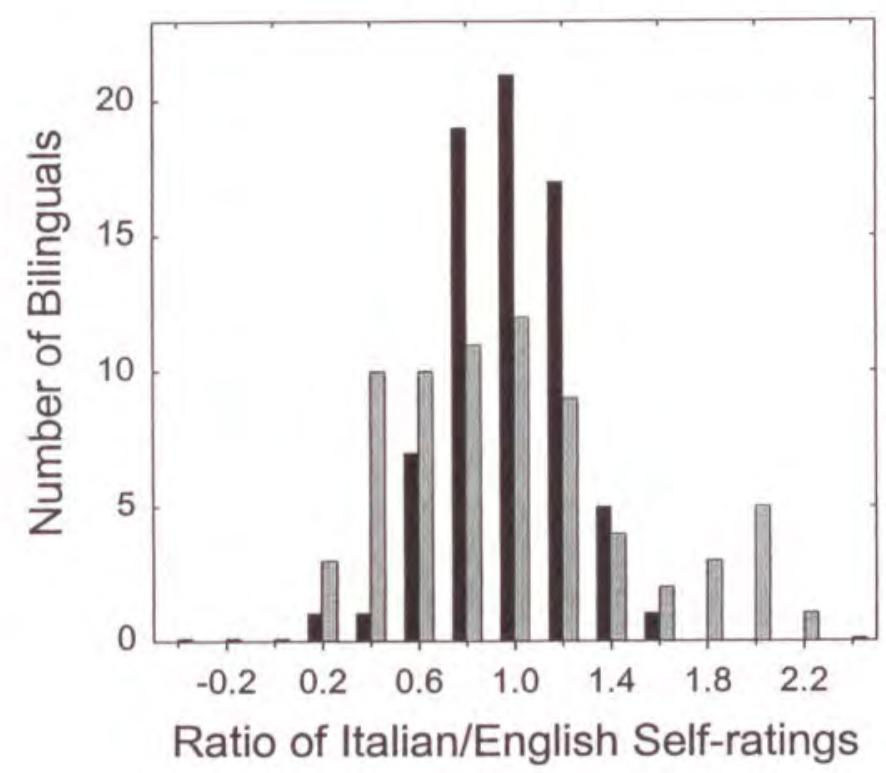

Figure 1. The frequency ratios of the self-rated ability to speak and understand and to read and write Italian compared to English obtained from 72 bilinguals.

dominant in Italian, $\chi(1)=28.1, p<.01$. More early than late bilinguals (33 vs. 2) showed written dominance in English, $\chi(1)=27.5, p<.01$, whereas fewer early than late bilinguals ( 1 vs. 30 ) showed written dominance in Italian, $\chi(1)=$ $27.1, p<.01$. On the other hand, there was not a significant difference in the number of high L1 use and low L1 use bilinguals showing verbal dominance in English (14 vs. 20$), \chi(1)=1.06, p>.10$, or in Italian (19 vs. 13$), \chi(1)=1.12$, $p>.10$. Nor was there a significant difference in the number of high L1 use and low L1 use bilinguals showing written dominance in English (15 vs. 20), $\chi(1)=.71, p>.10$, or in Italian (18 vs. 13$), \chi(1)=.81, p>.10$.

Analyses of the discrete classifications suggested that bilingual dominance patterns are not affected by $\mathrm{L} 1$ use. However, analyses of self-rating ratios suggested otherwise. Two ratios were calculated for each bilingual: verbal dominance (the average self-rated ability to speak and understand Italian divided by the average self-rated ability to speak and understand English) and written dominance (the average self-estimated ability to read and write Italian divided by the self-estimated ability to read and write English).

Figure 1 is a histogram showing the distribution of verbal and written dominance ratios obtained for the 72 Italian-English bilinguals. Neither the verbal ratios $(M=0.98, S D=0.26)$ nor the written $\operatorname{ratios}(M=1.07, S D=0.64)$ differed significantly from a value that might be taken to indicate bilingual balance, that is, a ratio of 1.0 ( $p>.10$ according to one-sample $t$ tests). The verbal and written ratios correlated significantly, $r(70)=.79, p<.01$. However, there was a wider range of written ratios $(0.14-3.5)$ than verbal ratios $(0.29-$ 
Flege et al.: Assessing bilingual dominance

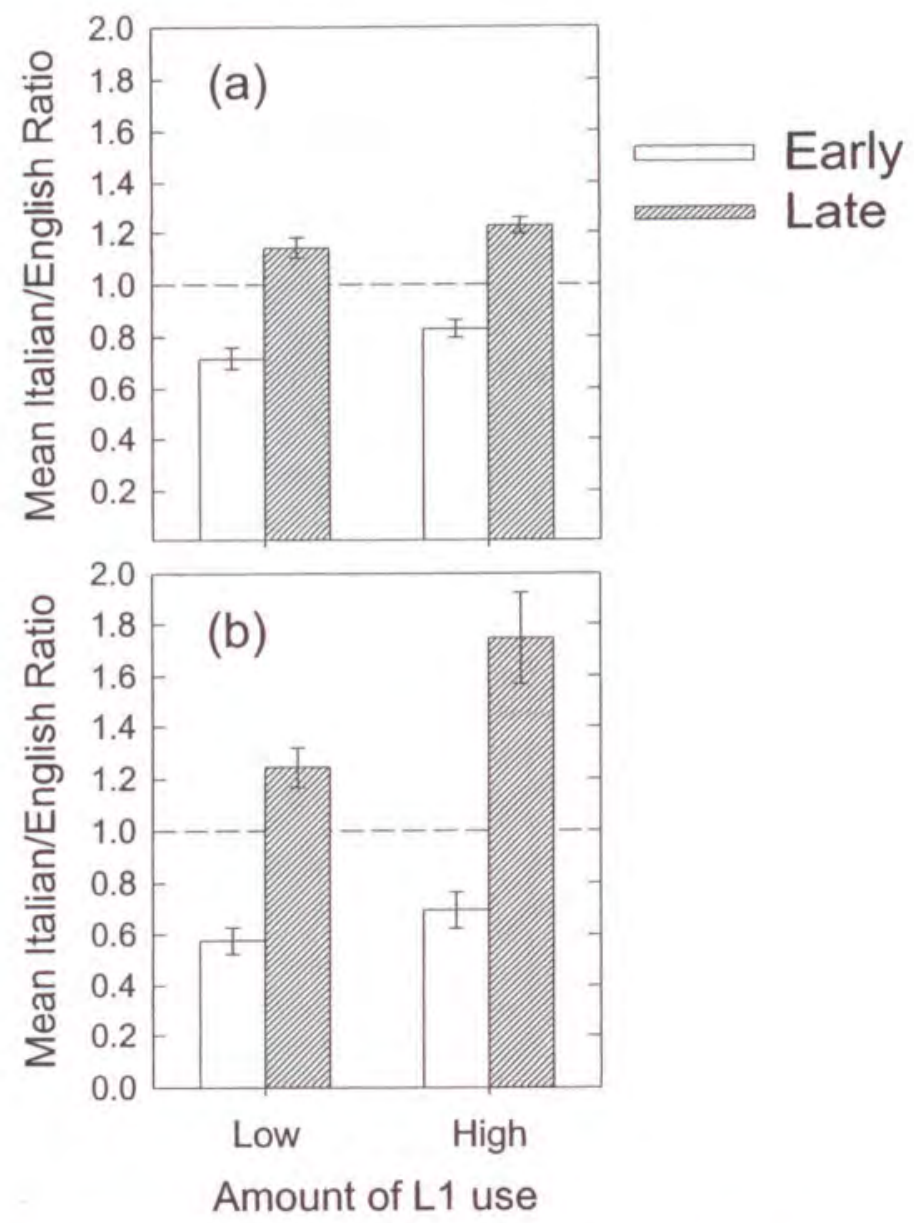

Figure 2. (a) The mean ratios of the self-reported ability to speak and understand Italian compared to English obtained for four groups of Italian-English bilinguals; (b) the mean ratios of the ability to read and write Italian compared to English. The error bars enclose $\pm 1 S E$.

1.57), probably because years of education in Italian-speaking schools in Italy and English-speaking schools in Canada varied considerably (Italy: 0-18 years; Canada: 0-24 years). In fact, nearly half of the late bilinguals (late low: 6; late high: 9) had received formal education in Italy but not Canada, and half of the early bilinguals (early low: 10; early high: 6) had received formal education in Canada but not Italy.

The mean verbal and written self-rating ratios obtained for the four bilingual groups are shown in the two panels of Figure 2. Higher mean ratios were obtained for the late bilinguals than the early bilinguals (verbal: 1.18 vs. 0.78 ; written: 1.50 vs. 0.64 ), and for high L1 use than low L1 use bilinguals (verbal: 1.03 vs. 0.93 ; written: 1.22 vs. 0.91 ). The verbal and written self-rating ratios were examined in separate $2(\mathrm{AOA}) \times 2$ (L1 use) ANOVAs. A significant main effect of AOA was obtained for both the verbal ratios, $F(1,68)=123.2, p<$ .01 , and the written ratios, $F(1.68)=66.5, p<.01$.

Unlike the analyses of discrete classifications, significant differences between 
the high L1 use and low L1 use bilinguals were observed here for both the verbal bilingual dominance ratios $F(1,68)=7.2, p<.01$, and the written bilingual dominance ratios, $F(1,68)=8.7, p<.01$. The lack of AOA by L1 use interactions, verbal: $F(1,68)=.2, p>.10$; written: $F(1,68)=3.3, p>.05$, indicated that the L1 use differences were comparable for the early and the late bilinguals. This finding supports the view that continuous measures, such as ratios, provide a more sensitive method for selecting bilingual participants than discrete classifications do (see Grosjean, 1998, p. 144, for further discussion). The discrete measures of bilingual dominance will therefore not be discussed further in this article.

When taken together, the results presented here suggest that both the age of L2 learning and language use patterns are associated with differences in bilingual dominance. The bilinguals who were most likely to be Italian dominant arrived in Canada as young adults and continued to use Italian frequently whereas the bilinguals who were most likely to be English dominant arrived in Canada as children and used Italian relatively seldom.

\section{BILINGUAL DOMINANCE BASED ON SENTENCE DURATION RATIOS}

Analyses of the self-rating ratios presented in the last section suggested that bilingual dominance is affected by both AOA and L1 use. The purpose of the experiment presented in this section was to determine if the same conclusion could be derived from an objective measure of bilingual dominance.

The measure of bilingual dominance examined here was the ratio of the mean duration of English compared to Italian sentences. The sentences were repeated without instruction as to speaking rate. The method used here was adopted after considering several other methods used previously (see the Introduction). Mägiste (1992) obtained evidence in a picture-naming task that native German children and teenagers living in Stockholm switched from L1 dominance to L2 dominance. After a number of years of residence in Sweden, the children began to name pictures of familiar objects faster in Swedish than German, due to a decrease in latencies for L2 words and an increase for L1 words. More recently, Kohnert et al. (1998) used a picture-naming task to assess dominance in native Spanish children living in the United States. We decided against using a picture naming task, however, because of difficulty in controlling for lexical familiarity. Mägiste (1992) found that the time needed by the German children to become Swedish dominant varied as a function of age for the naming of pictures but not digits. This suggested that the size of the lexicon and lexical familiarity factors likely to vary across samples of bilinguals - may affect picture naming latencies.

Other research (Favreau \& Segalowitz, 1982, 1983; Macnamara, 1969) has suggested that the time needed to read comparable L1 and L2 texts as rapidly as possible may provide a useful index of bilingual dominance. However, several factors led us to decide against using this technique. It might prove difficult or impossible to match texts for lexical familiarity for diverse groups of bilinguals. Moreover, a reading task assumes equal reading ability across groups of bilinguals and might not generalize to speaking and understanding. Finally, 
differences are likely to exist in terms of how individuals respond to the instruction to read "as rapidly as possible." For example, some bilinguals but not others might be willing to shorten unstressed vowels or simplify consonant clusters. The resulting differences in duration might reflect differences in the ability or willingness to style shift rather than differences in bilingual dominance.

The measure of bilingual dominance presented here was the ratio of the mean duration of English and Italian sentences that were repeated following aurally presented models. Previous research has shown that the duration of L2 sentences is positively correlated with AOA (or, more generally, the age of first exposure to the L2) and inversely correlated with proficiency in the L2 (Elsendoorn, 1984; Guion, Flege, Liu, \& Yeni-Komshian, 2000; Pennington, 1992; Raupauch, 1980; Riggenbach, 1991; Sabin, Clemmer, O'Connell, \& Kowal, 1979). To our knowledge, no previous research has examined the effect of AOA on the duration of $\mathrm{L} 1$ sentences. If the duration of $\mathrm{L} 1$ sentences is unaffected by or inversely correlated with AOA (the opposite of what holds true for L2 sentences), then one would expect early bilinguals to produce shorter L2 than L1 sentences and late bilinguals to produce shorter L1 than L2 sentences. If so, then the sentence duration ratios should be greater than 1.0 for late bilinguals, indicating dominance in Italian, but less than 1.0 for early bilinguals, indicating dominance in English.

\section{Method}

An adult female native speaker of English produced the 12 English sentences shown in Appendix A, and an adult female native speaker of Italian produced the corresponding 12 Italian sentences. The 12 pairs of sentences were matched for number of words and syllables, and had the same or similar meanings. An adult female native speaker of Italian produced the corresponding 12 Italian sentences. (Most of the 24 sentences were derived from sentences developed for another purpose by Ooyen, Cutler, \& Bertinetto, 1993.) The two talkers' productions of the sentences were digitized $(22.05 \mathrm{kHz}, 16$-bit amplitude resolution) and normalized for peak intensity. Each sentence was then measured from the onset to the offset of phonetically relevant acoustic energy from time domain waveforms shown on the screen of a PC. The English sentences were somewhat shorter than the Italian sentences ( $M=2548$ vs. $2796 \mathrm{~ms}$ ), either because the talkers spoke at somewhat different rates, because of differences in the segmental composition of the two sets of sentences (e.g., only the Italian contained geminate consonants), or both.

The bilinguals' task was to repeat the English and Italian sentences just described. The sentences were presented via a loudspeaker, without prior instruction regarding speaking rate, in the order shown in Appendix A. English was the language of the first member of six pairs and Italian was the language of the first member of the remaining six pairs. The bilinguals were provided with a written list of sentences to be repeated. Each sentence was presented twice in a row, followed by a pure tone. The participants were told to repeat each sentence "accurately" a single time following the tone.

The sentences elicited in this way were recorded (Sony Model TDC-D9) us- 
Flege et al.: Assessing bilingual dominance

Table 4. Mean duration of the English and Italian sentences produced by four groups of bilinguals

\begin{tabular}{lccc}
\hline \hline & English & Italian & $M$ \\
\hline Early low & $2384(186)$ & $2593(206)$ & $2489(221)$ \\
Early high & $2405(162)$ & $2538(170)$ & $2472(177)$ \\
Late low & $2427(193)$ & $2394(238)$ & $2411(214)$ \\
Late high & $2585(283)$ & $2450(254)$ & $2518(274)$ \\
$M$ & $2450(219)$ & $2495(230)$ & \\
\hline \hline
\end{tabular}

Note: Each mean is based on 144 observations (18 bilinguals $\times 8$ ). Standard deviations are in parentheses.

ing a directional head-mounted microphone (Shure SM10A), and then digitized $(22.05 \mathrm{kHz})$. A research assistant measured each sentence to the nearest $\mathrm{ms}$ from the beginning of acoustic energy associated with the first phonetic segment to the end of acoustic energy associated with the last phonetic segment. Measurement reliability was acceptable. The mean difference between the original measurements and remeasurements of 48 randomly selected sentences made two weeks later was $20 \mathrm{~ms}$ (less than $1 \%$ ). The average, unsigned difference in the 48 pairs of measurements was $32 \mathrm{~ms}(1.3 \%)$. The first author's measurements of the 48 sentences differed from the assistant's by $10 \mathrm{~ms}$, on the average.

To avoid list series effects, the analyses presented here focused on the middle eight pairs of sentences. Only fluently produced sentences were measured. A total of $80(13.8 \%)$ English and $53(9.2 \%)$ Italian sentences were excluded. Sentences were excluded from analysis due to the omission or substitution of one or more words, the presence of ambient noise or laughter, an unfilled pause longer than $200 \mathrm{~ms}$, or a filled pause exceeding $150 \mathrm{~ms}$ (see Guion et al., 2000). The missing values were replaced using the multiple imputation method (Little \& Rubin, 1987). The mean duration of the English and Italian sentences produced by each bilingual was then calculated.

\section{Results and discussion}

As shown in Table 4, the mean duration of English and Italian sentences produced by the four groups of bilinguals differed little overall. Early bilinguals in the early low and early high groups produced shorter English than Italian sentences, whereas late bilinguals in the late low and late high groups produced longer English than Italian sentences. The duration of L2 utterances is known to influence listeners' judgments of global foreign accent (Munro, 1999) and fluency (Cucchiarini, Strik, \& Boves, 2000). However, the differences just reported should probably not be attributed to differences in fluency because only fluently produced sentences were measured.

Bilingual dominance was estimated by dividing the mean duration of English sentences by the mean duration of the corresponding Italian sentences. (We examined $\mathrm{L} 2 / \mathrm{L} 1$ duration ratios rather than $\mathrm{L} 1 / \mathrm{L} 2$ ratios so that, as for the self- 
Flege et al:: Assessing bilingual dominance

Table 5. Mean duration of the English and Italian sentences produced by four groups of bilinguals

\begin{tabular}{lccccc}
\hline \hline & Verbal & Written & AOA & L1 use & LOR \\
\hline Sentence ratios & $.68^{* *}$ & $.55^{* *}$ & $.70^{* *}$ & $.30^{* *}$ & $-.52^{* *}$ \\
Verbal ratios & & $.79^{* *}$ & $.78^{* *}$ & $.36^{* *}$ & $-54^{* *}$ \\
Written ratios & & & $.69^{* *}$ & $.42^{* *}$ & $-.45^{* *}$ \\
AOA & & & & .18 & $-.66^{* *}$ \\
L1 use & & & & -.12 \\
\hline \hline
\end{tabular}

Note: Sentence ratios, ratio of the mean duration of English compared to Italian sentences; verbal ratios, ratios of self-rated ability to speak and understand Italian compared to English; written ratios, ratios of self-rated ability to read and write Italian compared to English; AOA, age of arrival in Canada; L1 use, average selfreported percentage use of Italian; LOR, length of residence in Canada.

${ }^{*} p=.05 ; * * p=.01 ; d f=70$.

rating ratios reported earlier, larger values were associated with dominance in Italian.) The mean sentence duration ratio obtained for the 72 bilinguals was $0.99(S D=0.08)$. This did not differ significantly from a value that might be taken to indicate bilingual balance (i.e., a ratio of 1.0) in a one-sample $t$ test $(t=-1.56, p>.10)$. However, the sentence duration ratios obtained for individual participants differed considerably, ranging from 0.82 (suggesting dominance in English) to 1.15 (suggesting dominance in Italian).

Pearson correlations were computed to examine the relation between the sentence duration ratios and the written and verbal self-rating ratios obtained in the last section. We also examined the relation between the objective and subjective measures of bilingual dominance (i.e., the sentence duration and self-rating ratios) and three variables that are frequently used to select participants in L2 acquisition studies: AOA, percentage L1 use, and LOR. The correlations between all of these variables are shown in Table 5. The sentence duration ratios showed significant positive correlations with the verbal self-rating ratios $(r=$ $.68)$, and the written self-rating ratios $(r=.55)$. The sentence duration ratios were also correlated with AOA, L1 use, and LOR, as were the verbal and written self-rating ratios. These correlations suggested that the later in life the bilinguals had arrived in Canada, the fewer years they tended to have resided in Canada, and the more often they used Italian, the more dominant in Italian the bilinguals tended to be.

The mean sentence duration ratios obtained for the four bilingual groups are shown in Figure 3. Higher ratios were obtained for late than early bilinguals (1.04 vs. 0.94), and for high L1 use than low L1 use bilinguals (1.00 vs. 0.97). Given that the sentence duration ratios were correlated with the self-rating ratios presented in the last section, we expected to observe the same effect of AOA and L1 use as was reported earlier for the self-rating ratios. This was indeed the case. A two-way ANOVA examining the sentence duration ratios yielded a 


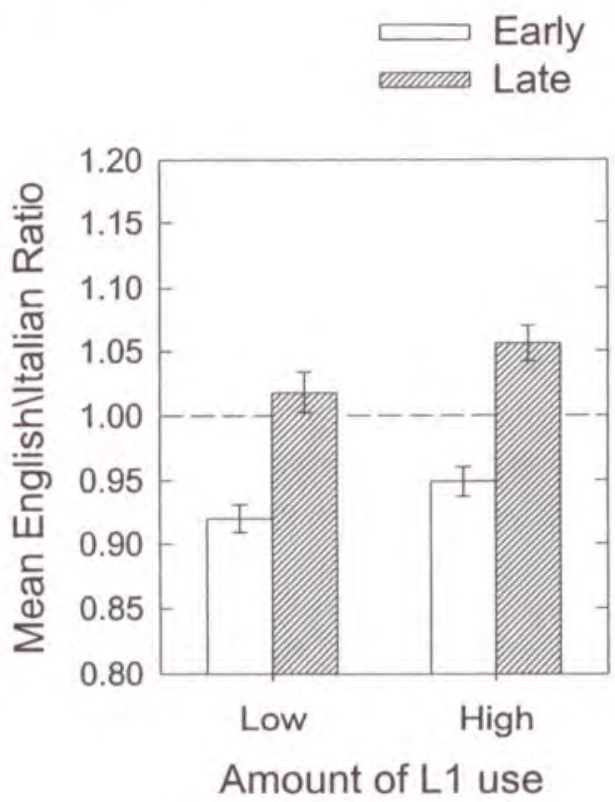

Figure 3. The mean ratio of the average duration of English compared to Italian sentences produced by four groups of Italian-English bilinguals. The error bars enclose $\pm 1 S E$.

significant main effect of AOA, $F(1,68)=60.3, p<.01$, a significant main effect of L1 use, $F(1,68)=6.5, p<.05$, and a nonsignificant two-way interaction, $F(1,68)=0.15, p>.10$.

\section{THE RELATION BETWEEN BILINGUAL DOMINANCE AND L2 PERFORMANCE}

This section assesses the relation between L2 performance and the bilingual dominance ratios presented in the last two sections. The measure of L2 performance examined here, overall degree of foreign accent in English sentences, will be described below. Stepwise regression analyses were carried out to compare the amount of variance in L2 performance accounted for by the bilingual dominance ratios, on the one hand, and by three variables used to select bilinguals in L2 acquisition research (AOA, percentage L1 use, and LOR), on the other. Finally, we examined the amount of variance accounted for by the dominance ratios when they were entered following AOA, L1 use, and LOR (and vice versa) in hierarchical regression analyses. The purpose of these analyses was to determine if the bilingual dominance ratios accounted for variance in L2 performance independently of AOA, L1 use, and LOR.

\section{Method}

The foreign accent ratings used here as a measure of the Italian-English bilinguals' performance in English were obtained in a study by Piske and colleagues (2001). Briefly, fluent productions of three English sentences (Paul ate carrots 
Flege et al.: Assessing bilingual dominance

and peas; I can read this for you; He turned to the right) were obtained using a delayed repetition technique. (A filled delay occurring between aurally presented models of the sentences and repetitions of them prevented direct imitations.) The bilinguals' sentences were digitized $(22.05 \mathrm{kHz})$, normalized for peak intensity, and then randomly presented three times each to native speakers of Canadian English. The listeners (four males, five females) had a mean age of 31 years. They used a scale ranging from 1 (very strong foreign accent) to 9 (no foreign accent) to rate the sentences. An intraclass correlation coefficient of $\rho=0.99, F(89,712)=93.5, p<.01$, indicated a high level of interrater reliability. Accordingly, a mean rating was obtained for each of the 72 bilinguals and 18 native English speakers. Each mean was based on 81 judgments $(9$ Listeners $\times 3$ Sentences $\times 3$ Presentations).

\section{Results and discussion}

Piske et al. (2001) examined the mean ratings obtained for the bilinguals in a 2 $(\mathrm{AOA}) \times 2$ (L1 use) ANOVA. This analysis indicated that the late bilinguals' sentences obtained significantly lower ratings - indicating stronger foreign accents - than the early bilinguals' sentences $(p<.01)$. Significantly lower ratings were also obtained for sentences produced by the high L1 use than the low L1 use bilinguals $(p<.01)$. The lack of a significant interaction between AOA and L1 use $(p>.10)$ indicated that the effect of L1 use was comparable for early and late bilinguals. Another analysis carried out by Piske et al. examined the ratings obtained for sentences produced by the native English speakers and the four groups of bilinguals. It revealed that sentences produced by all four groups of bilinguals obtained significantly lower ratings than the native English speakers' sentences $(p<.01)$. This finding, which indicated that even the two groups of early bilinguals produced the English sentences with detectable foreign accents, replicated results obtained previously (Flege et al., 1995b; Flege, Frieda, \& Nozawa, 1997; Guion, Flege, \& Loftin, 2000; Yeni-Komshian, Flege, \& Liu, 2000).

Our primary interest here was the relation between the foreign accent ratings and bilingual dominance. The foreign accent ratings showed significant correlations with all three bilingual dominance ratios reported earlier, sentence duration ratios: $r(70)=-.74, p<.01$; verbal self-rating ratios: $r(70)=-.75, p<.01$; written self-rating ratios: $r(70)=-.68, p<.01$. Given that ratios greater than 1.0 indicated dominance in Italian and all three correlations were inverse, these findings suggested that dominance in Italian was associated with relatively strong foreign accents in English.

Multiple regression analyses were carried out to examine the predictive power of the bilingual dominance ratios, on the one hand, and AOA, L1 use, and LOR, on the other. These analyses were motivated by the fact that AOA, L1 use, and LOR were correlated with degree of foreign accent in English, AOA: $r(70)=$ $-.83, p<.01$; L1 use: $r(70)=-.41, p<.01$; LOR: $r(70)=.47, p<.01$; and also with the bilingual dominance ratios (see Table 5). The three measures of bilingual dominance accounted for $65.8 \%$ of the variance in L2 performance, $F(2$, $69)=66.2, p<.01$ (verbal dominance ratios: $55.9 \%$, sentence duration ratios: 
9.9\%). AOA, L1 use, and LOR accounted for $75.5 \%$ of the variance, $F(2,69)=$ 106.2, $p<.01$ (AOA: $68.4 \%, \mathrm{~L} 1$ use: $7.1 \%$ ).

The analyses just presented suggested that the bilingual dominance ratios were somewhat less successful in predicting L2 performance than AOA, L1 use, and LOR. A hierarchical regression analysis in which the three measures of bilingual dominance were entered after AOA, L1 use, and LOR were carried out to determine if the bilingual dominance ratios accounted for any variance independently of these three variables. AOA and L1 use accounted for 68.4 and $7.1 \%$ of the variance, respectively, at Step 1. At Step 2, the sentence duration ratios accounted for an additional $2.5 \%$ of the variance, $F(3,68)=80.4, p<$ .01. A second hierarchical regression analysis, in which the two sets of criterion variables were entered in the opposite order accounted for $79.6 \%$ of the variance in L2 performance, $F(5,66)=51.6, p<.01$. Two measures of bilingual dominance were identified as significant predictors at Step 1 (verbal dominance ratios: $55.9 \%$, sentence duration ratios $9.9 \%$ ). At Step 2, all three other variables were identified as significant predictors: AOA ( $8.6 \%$ of the variance), L1 use (3.8\%), and LOR (1.5\%).

In summary, three variables often used to select participants in L2 acquisition research (AOA, L1 use, LOR) accounted for somewhat more variance in L2 performance than three measures of bilingual dominance did (75.5 vs. 65.8\%). When AOA, L1 use, and LOR were entered in a regression analysis following bilingual dominance ratios, they accounted for an additional $13.9 \%$ of the variance; conversely, when three bilingual dominance ratios were entered after AOA, L1 use, and LOR, a small $(2.5 \%)$ but significant amount of additional variance was accounted for. These findings suggest that measures of bilingual dominance are linked closely to variables examined in L2 research (AOA, percentage L1 use, LOR) but may not be fully equivalent to those variables.

\section{THE RELATION BETWEEN BILINGUAL DOMINANCE AND L1 PERFORMANCE}

The aim of this section was to assess the relation between the bilingual dominance ratios presented earlier and a measure of the bilinguals' performance in Italian. The measure of L1 performance used here was the ability to translate English sentences into Italian. First, the effect of AOA and L1 use on translation ability was examined in a two-way ANOVA. Next, regression analyses were carried out to examine the relation between L1 performance (i.e., the sentence translation scores) and both the bilingual dominance ratios and AOA, L1 use, and LOR.

\section{Method}

Two factors led us to evaluate L1 performance by having the bilinguals translate English sentences into Italian. It was not possible to carry out a foreign accent experiment with Italian sentences that was analogous to the experiment examining the bilinguals' pronunciation of English sentences. This is because the Italian-English bilinguals had learned many different regional variants and dia- 
Flege et al.: Assessing bilingual dominance

lects of Italian as an L1. Their pronunciation of Italian sentences might therefore have been downgraded by native Italian-speaking listeners in the absence of an influence from English. Second, the fact that many of the bilinguals had received little education in Italy ${ }^{3}$ ruled out the use of standardized tests of Italian.

The bilinguals were asked to translate the 30 English sentences shown in Appendix B into Italian. These sentences represented 10 diverse domains of everyday life and were graded for difficulty (three levels, Sets A-C). The English sentences used to elicit the translations were produced by an adult male native speaker of Canadian English. These sentences were digitized $(22.05 \mathrm{kHz})$, normalized for peak intensity, and then presented twice in a row via a loudspeaker in order of increasing difficulty (Sets A-C).

The bilinguals were told to translate as much of each English sentence into Italian as possible. They were given an opportunity to ask for clarification of the meaning of any English sentence, as needed, before attempting a translation. The bilinguals attempted to translate $92 \%$ of the relatively "easy" sentences in Set A, but only $77 \%$ of the sentences in Sets B and C. The late bilinguals attempted to translate more sentences than the early bilinguals did ( $M=89$ vs. $74 \%$ ), but there was little difference between the low L1 use and high L1 use bilinguals ( $M=81$ vs. $83 \%$ ). Of the 72 bilinguals, 59 attempted 20 or more of the 30 sentences, 12 attempted 14-19 sentences, and 1 participant, a 45-yearold male in the early low group who had arrived in Canada at the age of 5 years, did not attempt any of the sentences. ${ }^{4}$

The bilinguals' translations were recorded (Sony model TDC-D9), digitized $(22.05 \mathrm{kHz})$, and then normalized for peak intensity for later off-line evaluation. Repetitions, prolonged pauses, or extraneous comments ("Oh, I can't say that!"), if any, were edited out before the attempted translations were presented, in counterbalanced order, to six adult native speakers of Italian. The listeners rated each attempted translation using a scale that ranged from 1 for sentences that rendered none of the meaning of an English sentence appropriately into Italian to 5 for sentences in which all of the meaning of an English sentence was rendered appropriately into Italian. The listeners were informed that the bilinguals were speakers of regional variants and dialects of Italian who had immigrated to Canada. They were instructed to ignore regional or dialectal characteristics of the sentences, including pronunciation, insofar as possible. The listeners were also told that there was more than one possible correct translation for most sentences.

The listeners were required to rate each attempted translation. The interval between each rating and presentation of the next sentence was $1.0 \mathrm{~s}$. An attempted translation could be replayed, but ratings could not be changed once given. Five extra translations at the beginning of each block of sentences were not analyzed. Sentences the bilinguals did not attempt to translate (see above) were assigned the lowest possible rating (1). A detailed analysis of syntactic errors, lexical errors, and number of omitted words (Roberts, MacKay, \& Flege, 2002) revealed effects of AOA but not L1 use. The analyses presented here focused on the overall ability to translate, however. The median of ratings given by the six listeners to each sentence was determined; then an average over the 30 sentences was computed. 


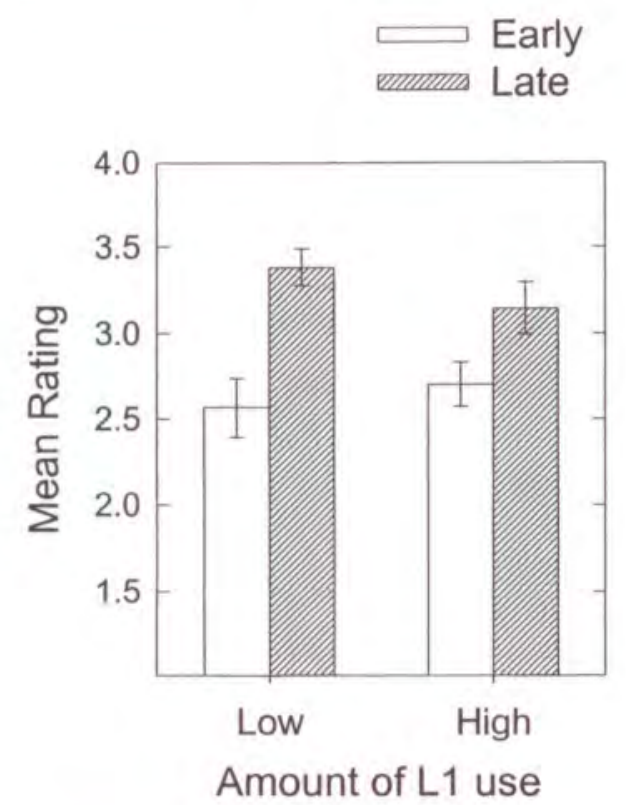

Figure 4. The mean ratings of the translations of 30 English sentences into Italian by four groups of Italian-English bilinguals. The error bars enclose $\pm 1 S E$.

Grosjean (1997) suggested that bilinguals might perform a translation task poorly, even if they speak both of their languages well, if they have had little prior experience translating between their two languages. Also, it seems reasonable to think that bilinguals might translate more effectively in an actual bilingual conversation than in a laboratory setting. We therefore asked the bilinguals to rate their own ability to translate each sentence prior to attempting to do so vocally (see above). They used a 3-point scale to evaluate their own ability. The bilinguals used a rating of 1 to indicate that they could not translate a particular English sentence into Italian, 2 to indicate an ability to translate a sentence within the context of a bilingual conversation but not during the experiment, and 3 to indicate an ability to translate a sentence. The bilinguals' average selfratings were correlated with the scores obtained from the native Italian listeners, $r(70)=.84, p<.01$, and will not be discussed further.

\section{Results and discussion}

The sentence translation scores are shown in Figure 4. Higher scores were obtained for the late bilinguals than for the early bilinguals ( $M=3.3$ vs. 2.6), whereas the scores obtained for the high L1 use and the low L1 use bilinguals $(M=2.9$ vs. 3.0$)$ differed little. A two-way ANOVA examining the sentence translation scores yielded a significant main effect of AOA, $F(1,68)=19.7$, $p<.01$, a nonsignificant main effect of L1 use, $F(1,68)=.13, p>.10$, and a nonsignificant interaction $F(1,68)=1.7, p>.10$. The lack of an effect of L1 use on L1 performance differed from the finding reported earlier for L2 performance, where it was found that bilinguals who used Italian often had stronger 
foreign accents in English than those who used Italian seldom. The fact that using Italian seldom did not result in a lowering of the translation scores suggests that a frequent use of Italian was not a prerequisite for maintaining the L1. However, this conclusion must be considered tentative, because an L1 use effect might have been observed had a more sensitive measure of L1 performance been used or some other aspect of L1 performance been tested.

A stepwise multiple regression analysis was carried out to examine the relation between the translation scores and the three bilingual dominance ratios reported earlier. It accounted for $29.0 \%$ of the variance, $F(2,69)=14.1, p<.01$ (verbal self-ratings ratios: $21.9 \%$; written self-rating ratios: $7.1 \%$ ). A regression analysis examining the relation between the sentence translation scores and AOA, L1 use, and LOR was motivated by the fact that two of these variables were correlated with the sentence translation scores, AOA: $r(70)=.45, p<.01$; LOR: $r(70)=-.33, p<.01$; L1 use: $r(70)=-.01$, $n s$; and all three were correlated with the bilingual dominance ratios (see Table 5). The second stepwise regression analysis accounted for less variance $(20.1 \%)$ than the first analysis, $F(1,70)=17.7, p<.01$. (AOA was identified as the only significant predictor of $\mathrm{L} 1$ performance.)

A hierarchical regression analysis was carried out to determine if the bilingual dominance ratios accounted for some of the variance in L1 performance independently of AOA, L1 use, and LOR. In this analysis, the three bilingual dominance ratios were entered at Step 2, following AOA, L1 use, and LOR. The bilingual dominance ratios did not account for a significant additional amount of variance in the sentence translation scores $(p>.05)$. In a second analysis, AOA, L1 use, and LOR did not account for a significant additional amount of variance in the sentence translation scores when entered following the three bilingual dominance ratios $(p>.05)$.

\section{PERFORMANCE OF ENGLISH-DOMINANT AND ITALIAN-DOMINANT BILINGUALS}

The regression analyses presented in the last two sections suggested that bilingual dominance ratios accounted for more variance in L2 than L1 performance (66 vs. $29 \%$ ) and were correlated with AOA, L1 use, and LOR (which also accounted for more variance in L2 than L1 performance, 76 vs. 20\%). Differences in the prediction of L2 and L1 performance may have arisen because the measure of L2 performance examined here, overall degree of foreign accent in English sentences, was more fine-grained than the measure of L1 performance, ability to translate English sentences into Italian. Another possibility is that variation in $\mathrm{Ll}$ performance was constrained due to the fact that the experiment was administered in English by an English-speaking experimenter (see Grosjean, 1998).

The ability of the bilingual dominance measures and AOA, L1 use, and LOR to predict L1 and L2 performance differed. The bilingual dominance ratios accounted for less variance in L2 performance than AOA, L1 use, and LOR (66 vs. $76 \%$ ) whereas they accounted for somewhat more variance in L1 performance than the latter three factors $(29$ vs. $20 \%)$. Another difference was evident 
Flege et al.: Assessing bilingual dominance

when the measures of bilingual dominance were entered following AOA, L1 use, and LOR in hierarchical regression analyses. One measure of bilingual dominance (i.e., the sentence duration ratios) accounted for a small but significant additional amount of variance in L2 performance; however, none of the bilingual dominance ratios accounted for a significant additional amount of variance in $\mathrm{L} 1$ performance.

When taken together, these results suggested that bilingual dominance patterns are related to AOA, L1 use, and LOR but are somewhat independent of those variables. The aim of this section, therefore, was to provide a profile of the bilinguals who were L1 dominant and L2 dominant and to examine differences in L1 and L2 performance between groups selected on the basis of bilingual dominance ratios.

\section{Method}

Fifty-four of the 72 bilinguals were reassigned to one of three groups of 18 each based on their verbal self-rating ratios, written self-rating ratios, and sentence duration ratios. (The results presented below did not change when only the verbal ratios and sentence duration ratios were used or when only the sentence duration ratios were used.) The bilinguals were first rank-ordered in terms of the ratios. Next, the ranks (1-72) assigned to each bilingual were averaged. Finally, the bilinguals were assigned to one of three groups according to their average rank. The 18 bilinguals with the highest ranks (i.e., the highest ratios) were designated Italian dominant, whereas the 18 with the lowest ranks were designated English dominant. Eighteen bilinguals with ranks at the middle of the range were designated balanced. (Nine bilinguals with ranks intermediate to the Italian-dominant and balanced groups and nine with ranks between the balanced and English-dominant groups were not assigned to a group.)

\section{Results and discussion}

All 18 participants assigned to the English-dominant group were early bilinguals (early low: 12; early high: 6), whereas all 18 participants assigned to the Italiandominant group were late bilinguals (late low: 6; late high: 12). The group designated balanced consisted of both early bilinguals (early low: 4; early high: 6) and late bilinguals (late low: 4; late high: 4).

Table 6 presents characteristics of the three groups selected on the basis of bilingual dominance, along with the results of $F$ tests and post hoc tests comparing those groups. The ratios of the participants assigned to the English-dominant and the Italian-dominant groups did not overlap. The ratios of the participants assigned to the balanced group were compared to a value representing a hypothetical estimate of bilingual balance (i.e., a ratio of 1.0) in a series of onesample $t$ tests. In no instance did the balanced bilinguals' ratios differ significantly from 1.0 (Bonferroni $p>.05$ ). As expected, the three groups differed significantly in terms of the bilingual dominance ratios. Also, the three groups differed significantly in terms of AOA, percentage L1 use and LOR $(p<.01)$ but not in chronological age. The English-dominant bilinguals arrived in Canada 
Applied Psycholinguistics 23:4

Flege et al.: Assessing bilingual dominance

Table 6. Characteristics ( $M, S D$, range) of three groups of bilinguals who were classified as English dominant, balanced, or Italian dominant

\begin{tabular}{|c|c|c|c|c|c|}
\hline & $\begin{array}{l}\text { English } \\
\text { dominant }\end{array}$ & Balanced & $\begin{array}{c}\text { Italian } \\
\text { dominant }\end{array}$ & $F(2,51)$ & Post hoc \\
\hline$N$ & $6 \mathrm{~m}, 12 \mathrm{f}$ & $11 \mathrm{~m}, 7 \mathrm{f}$ & $8 \mathrm{~m}, 10 \mathrm{f}$ & - & - \\
\hline Age & $\begin{array}{l}49(5) \\
40-58\end{array}$ & $\begin{array}{l}50(5) \\
35-59\end{array}$ & $\begin{array}{l}50(8) \\
29-62\end{array}$ & 0.6 & - \\
\hline L1 use & $\begin{array}{c}19(20) \\
1-67\end{array}$ & $\begin{array}{c}31(24) \\
2-75\end{array}$ & $\begin{array}{c}39(22) \\
5-70\end{array}$ & $3.8^{*}$ & $1<3$ \\
\hline LOR & $\begin{array}{l}42(4) \\
36-50\end{array}$ & $\begin{array}{l}37(5) \\
29-47\end{array}$ & $\begin{array}{r}30(8) \\
4-38\end{array}$ & $17.2 * *$ & $1>2>3$ \\
\hline $\mathrm{AOA}$ & $\begin{array}{l}6(3) \\
2-11\end{array}$ & $\begin{array}{r}13(6) \\
2-23\end{array}$ & $\begin{array}{l}20(3) \\
15-25\end{array}$ & $52.9 * *$ & $1<2<3$ \\
\hline $\begin{array}{l}\text { Sentence } \\
\text { ratios }\end{array}$ & $\begin{array}{c}0.90(0.04) \\
0.82-0.97\end{array}$ & $\begin{array}{c}0.98(0.03) \\
0.92-1.05\end{array}$ & $\begin{array}{c}1.08(0.05) \\
0.99-1.15\end{array}$ & $87.0 * *$ & $1<2<3$ \\
\hline $\begin{array}{l}\text { Verbal } \\
\text { ratios }\end{array}$ & $\begin{array}{c}0.67(0.13) \\
0.29-0.86\end{array}$ & $\begin{array}{l}1.0(0.11) \\
0.83-1.27\end{array}$ & $\begin{array}{c}1.26(0.10) \\
1.08-1.40\end{array}$ & $118.8^{* *}$ & $1<2<3$ \\
\hline $\begin{array}{l}\text { Written } \\
\text { ratios }\end{array}$ & $\begin{array}{c}0.53(0.17) \\
0.14-0.86\end{array}$ & $\begin{array}{c}0.97(0.36) \\
0.21-2.00\end{array}$ & $\begin{array}{c}1.65(0.58) \\
1.00-3.50\end{array}$ & $34.7 * *$ & $1<2<3$ \\
\hline
\end{tabular}

Note: M, male; f, female; age, chronological age; L1 use, percentage use of Italian; LOR, length of residence in Canada; AOA, age of arrival in Canada; sentence ratios, ratios of the mean duration of English compared to Italian sentences; verbal ratios, ratios of self-rated ability to speak and understand Italian compared to English; written ratios, ratios of self-rated ability to read and write Italian compared to English. The post hoc tests were $t$ tests comparing all three groups (Bonferroni $p<.05$ ).

$* p=.05 ; * * p=.01$.

at an earlier age than the Italian-dominant bilinguals did ( $M=6$ vs. 20 years), had lived in Canada longer than the Italian dominant bilinguals had ( $M=42$ vs. 30 years), and reported using Italian less (19 vs. $39 \%)$.

An ANOVA examining L1 performance revealed that the sentence translation scores obtained by the three groups (English dominant: 2.44; balanced: 3.12; Italian dominant: 3.24$)$ differed significantly, $F(2,51)=10.8, p<.01$. A Tukey's post hoc test revealed that the Italian-dominant bilinguals and the balanced bilinguals obtained significantly higher scores than the English-dominant bilinguals did $(p<.05)$. The Italian-dominant bilinguals and the balanced bilinguals did not differ significantly, however.

The findings just reported suggest that dominance in the L2 is associated with relatively poor performance in the $\mathrm{L} 1$. The best interpretation of these findings is uncertain, however. The lower scores of the English-dominant bilinguals may have been due to the influence of English. The English-dominant bilinguals may have lost skills in Italian that they possessed earlier in life. Still another possibility is that the English-dominant bilinguals never possessed the skills needed to 
Flege et al.: Assessing bilingual dominance

perform the sentence translation task well if their development in Italian slowed or ceased when they immigrated to Canada at the average age of 6 years (range $=$ 2-11).

An ANOVA examining L2 performance revealed that the English foreign accent ratings obtained by the three groups (English dominant: 7.18; balanced: 4.92; Italian dominant: 2.64) differed significantly, $F(2,51)=51.7, p<.01$. A Tukey's post hoc test revealed that the Italian-dominant bilinguals had significantly stronger foreign accents than the balanced bilinguals, whose foreign accents were significantly stronger, in turn, than those of the English-dominant bilinguals $(p<.05)$.

The 54 Italian-English bilinguals considered here were originally assigned by Piske et al. (2001) to one of four groups based on AOA and L1 use. The sentences spoken by all four groups of bilinguals examined by Piske et al. (early low, early high, late low, late high) received significantly lower $(p<.01)$ ratings than native English speakers' sentences $(M=8.06)$. This indicated that even the two groups of early bilinguals had detectable foreign accents (see also Flege et al., 1995b, 1997; Guion et al., 2000; Yeni-Komshian et al., 2000). It is worth noting, however, that 11 early bilinguals examined by Piske et al. (early low: 9; early high: 2) received foreign accent ratings that fell within the native speaker range.

The purpose of the final analysis was to determine if all three groups selected on the basis of bilingual dominance ratios (viz., the English-dominant, balanced, and Italian-dominant groups) would also differ from the native English group. An ANOVA examining the foreign accent ratings obtained for the native English speakers and the three new groups was significant, $F(3,68)=77.6, p<$ .01. A series of a posteriori $t$ tests revealed that the balanced and Italian-dominant bilinguals' sentences received significantly lower ratings than the native English speakers' sentences (Bonferroni $p<.05$ ). However, the difference between the English-dominant bilinguals and native English speakers was nonsignificant. This suggested that early bilinguals who are dominant in their L2 may not speak their L2 with a detectable foreign accent.

\section{GENERAL DISCUSSION}

Both subjective and objective methods were used here to assess bilingual dominance in Italian-English bilinguals who had been selected on the basis of AOA in Canada and percentage use of Italian. Ratios were derived from the bilinguals' self-rated ability to speak and understand Italian compared to English (the verbal self-rating ratios) and to read and write Italian compared to English (the written ratios). The ratio of the mean duration of English and Italian sentences produced by each bilingual was also computed.

The sentence duration ratios showed a significant positive correlation with both the verbal self-rating ratios $(r=.68)$ and the written self-rating ratios $(r=$ .55). Also, the same effects of AOA and L1 use were obtained in analyses of the sentence duration ratios and the self-rating ratios. (All three ANOVAs yielded main effects of AOA and L1 use and nonsignificant two-way interactions.) This is because most late bilinguals and high L1 use bilinguals had ratios 
greater than 1.0, whereas most early bilinguals and low L1 use bilinguals had ratios less than 1.0. Thus, the bilinguals who were most likely to self-rate their abilities to be greater in Italian than English and to produce shorter Italian than English sentences were those who arrived in Canada as young adults and used Italian often. Conversely, the bilinguals who were most likely to self-rate their abilities to be greater in English than Italian and to produce longer Italian than English sentences were those who arrived in Canada as children and used Italian seldom.

Will the bilingual dominance patterns observed here generalize to other groups of early and late bilinguals? More research is needed to answer this question. As a preliminary, we computed self-rating ratios for the bilinguals examined by Yeni-Komshian et al. (2000). In that study, 240 Korean-English bilinguals used 5-point scales to self-rate their knowledge of English and Korean grammar and their ability to pronounce English and Korean, remember the pronunciation of English and Korean words, and read and write English and Korean. The mean Korean-English self-rating ratios obtained for the 72 bilinguals with AOAs less than 8 years was less than $1.0(M=.45$, range $=.20-.94)$, indicating dominance in English, whereas the ratios obtained for the 72 bilinguals with AOAs greater than 16 years was more than $1.0(M=1.52$; range = $1.00-3.00$ ), indicating dominance in Korean. (Both values differed significantly from 1.0 in one-sample $t$ tests, $p<.01$ ). When taken together with the results obtained here, this suggests that an early exposure to the L2 typically results in L2 dominance for bilinguals who learn English as an L2 upon immigrating to North America.

Yeni-Komshian et al. (2000) did not obtain percentage language use estimates, so it was not possible to determine if L1 use affected the Korean-English bilinguals as it affected the Italian-English bilinguals examined in the present study. However, in a study examining 807 Spanish-English bilinguals living in the United States, Bahrick et al. (1994) reported that a high self-reported frequency of English use was associated with dominance in English whereas a high self-reported use of Spanish was associated with dominance in Spanish. ${ }^{5}$ Percentage L1 use appeared to be somewhat more predictive of dominance than percentage L2 use.

Additional research will also be needed to establish whether the findings reported here for sequential bilinguals will apply to individuals who learned two languages simultaneously in early childhood, and to evaluate, for sequential bilinguals, the effect (if any) of variations in the relative social prestige and economic importance of the L1 and L2. A switch in dominance to the L2 may not be inevitable in child immigrants. Perhaps the early Italian-English bilinguals examined in this study became dominant in English as the result of using English at school and needing to use English to succeed economically, not because of their age upon first being exposed to English. One might hypothesize that fewer of the early Italian-English bilinguals would have become English dominant had they received instruction in both English and Italian in a bilingual school or if Italian had greater economic importance in Ottawa.

The similarity of results obtained here for the self-rating ratios and an objective measure of bilingual dominance, the sentence duration ratios, validate the 
use of self-ratings in assessing bilingual dominance (Goggin et al., 1994; Kohnert et al., 1998; Lemmon \& Goggin, 1989; Talamas et al., 1999). Our findings are consistent with the results of Bahrick et al. (1994), who found that SpanishEnglish bilinguals who self-rated their abilities to be greater in English than in Spanish generally obtained higher scores on matching English than Spanish performance tests, regardless of whether the self-ratings pertained to reading, writing, speaking, or understanding.

There is reason, however, to prefer the sentence duration ratios as an index of dominance over self-rating ratios. There is evidence that bilingual dominance may change over time (Jia \& Aaronson, 1999). One study suggesting that such changes occur was a cross-sectional study comparing German children who differed primarily according to length of residence in Sweden. Mägiste (1992) found that German children came to name pictures of familiar objects more rapidly in Swedish than in German. She attributed this change to a loss of automaticity in the L1 and to increased interference from the developing L2 system (see de Bot, 1992; Green, 1986; Meuter \& Alport, 1999). Additional longitudinal research is needed to determine the circumstance in which bilingual dominance changes. One reason to prefer sentence duration ratios over selfrating ratios as an index of bilingual dominance is that measurements of sentence duration are less likely to be subject to bias in longitudinal research than self-rating ratios are.

A second reason to prefer sentence duration ratios as an index of bilingual dominance was obtained here in regression analyses. Both the sentence duration ratios and the self-rating ratios were correlated with AOA, L1 use, and LOR. This suggested that the later the bilinguals arrived in Canada, the fewer years they had resided in Canada, and the more they used Italian, the more dominant in Italian they tended to be. Both the bilingual dominance ratios and the other set of variables (AOA, L1 use, LOR) accounted for a significant amount of variance in L2 performance (assessed here by examining overall degree of foreign accent in English sentences) and L1 performance (assessed by having the bilinguals translate English sentences into Italian). Dominance in Italian was associated with a relatively poor pronunciation of English and a relatively good ability to translate into Italian. More variance in L2 than L1 performance was accounted for by the bilingual dominance ratios ( 66 vs. $29 \%$ ), and also by AOA, L1 use, and LOR (76 vs. 20\%). None of the bilingual dominance ratios accounted for a significant additional amount of variance in L1 performance when entered after AOA, L1 use, and LOR in a hierarchical regression analysis. However, one measure of bilingual dominance, the sentence duration ratios, accounted for a small but significant amount of additional variance in L2 performance when entered following AOA, L1 use, and LOR.

These results suggest that although bilingual dominance is closely related to AOA, L1 use, and LOR, it is partially independent of these variables. To further test this conclusion, we reassigned some of the 72 bilinguals (originally assigned by Piske et al., 2001, to one of four groups of 18 bilinguals each as based on AOA and L1 use) to one of three groups of 18 each as based on bilingual dominance. One analysis examined the degree of foreign accent in English sen- 
Flege et al.: Assessing bilingual dominance

tences. Lambert (1990, p. 203) suggested that balanced bilinguals will show little interlingual interference. This led to the expectation that, of the three groups selected on the basis of dominance, the balanced bilinguals would be least likely to show an influence of their L1 (Italian) on pronunciation of their L2 (English), and would thus be the least likely of the three groups to have detectable foreign accents in English.

This expectation regarding balanced bilinguals was not confirmed, however. The Italian-dominant bilinguals had significantly stronger foreign accents than the balanced bilinguals, who had stronger foreign accents than the English-dominant bilinguals. Sentences produced by the balanced bilinguals and Italian-dominant bilinguals, but not by the English-dominant bilinguals, received significantly lower ratings than the native English speakers' sentences. This meant that, unlike groups of early bilinguals selected on the basis of AOA and L1 use (Flege et al., 1997; Guion et al., 2000; Piske et al., 2001; Yeni-Komshian et al., 2000), bilinguals selected on the basis of dominance in English did not have detectable foreign accents in English. This finding suggests that bilinguals who become dominant in their L2 may be able to suppress the influence of their L1 system when pronouncing L2 sentences.

Our tentative conclusion that L2-dominant bilinguals may avoid phonetic interference from the L1 when producing L2 sentences has important theoretical implications. According to the speech learning model (Flege, 1995), bilinguals differ from monolinguals because the phonic elements used to produce and perceive the L1 and L2 reside in a "common phonological space," and will thus inevitably influence one another. In support of this, Yeni-Komshian et al. (2000) observed an L1 influence on pronunciation of the L2 as well as an L2 influence on pronunciation of the L1. Very few of the 240 Korean-English bilinguals examined were found to speak both of their languages without a detectable foreign accent. It is possible, of course, that a fine-grained acoustic analysis of sentences produced by the English-dominant bilinguals would reveal subtle divergences from English phonetic norms that went undetected by the listeners who rated the sentences for foreign accent. However, if additional research confirms that L2-dominant early bilinguals can suppress the influence of the L1 system, the speech learning model (Flege, 1995) would need to be revised.

It would be worthwhile, in future research, to evaluate the magnitude of interlingual interference effects. Perhaps the magnitude of L1 effects on the L2 (or vice versa) will depend on differences in the strength of one language compared to the other (i.e., dominance). The magnitude of L1 on L2 effects may be greatest and L2 on L1 effects smallest in L1-dominant bilinguals, whereas L2 on L1 effects may be greatest and L1 on L2 effects smallest in L2-dominant bilinguals. Given the close association between age of learning and bilingual dominance, these hypotheses will need to be tested by comparing groups of participants who differ in dominance but have been matched for age of L2 learning (AOA). The dependent variables in such studies should be carefully matched measures of performance in the L1 and L2 (see, e.g., Bahrick et al., 1994). Such studies offer the promise of providing important new insight into how bilinguals organize and use their two languages. 
Flege et al.: Assessing bilingual dominance

\section{APPENDIX A}

These are the 12 pairs of English and Italian sentences that were repeated by the ItalianEnglish bilinguals. The Italian sentences are in italics.

The reporter has become cynical.

Lo scrittore mi sembra cinico.

La cura non era durevole.

This treatment never produces results.

Tom may undertake an analysis.

Pietro svolse poi un'analisi.

La prima formula sembra scorretta.

The second formula was erroneous.

The physician has written seven theses.

II dottore ha scritto una tesi.

Franco era noto per la cortesia.

Sammy was famous for his imagination.

Ben gave the response that everyone expected.

Giorgio dava la risposta che aspettavo.

La citta' ha molte tipiche caratteristiche.

The location has many typical characteristics.

The woman was not in critical condition.

La donna gli fece una critica severa.

Un' auto e' meno economica del tram.

My Chevrolet is more economical than his.

His philosophy was tremendously hard to understand.

II suo metodo era difficile da capire.

Un grave incidente causo' la paralisi di entrambe le gambe.

A very serious accident caused a paralysis of both his legs. 
Flege et al.: Assessing bilingual dominance

APPENDIX B

The 30 English sentences that were translated into Italian by the Italian-English bilinguals

\begin{tabular}{rll}
\hline Domain & Set & \multicolumn{1}{c}{ Sentence } \\
\hline 1 & A & I know people who are Catholic and Protestant. \\
2 & A & She set the table. \\
3 & A & Her skirts were made of cotton and silk. \\
4 & A & The man takes aspirin when he has a headache. \\
5 & A & Get a receipt from the cashier. \\
6 & A & She got in the front seat of the car. \\
7 & A & She is sincere but has no sense of humor. \\
8 & A & The house has a living room and a dining room. \\
9 & A & Some plants must be fertilized each spring. \\
10 & A & The referee blew his whistle. \\
1 & B & The altar boy burned incense on Palm Sunday. \\
2 & B & The man likes his meat rare, not well done. \\
3 & B & He likes his shirts loose, not tight fitting. \\
4 & B & He got the prescription filled at the pharmacy. \\
5 & B & He can never balance his checkbook. \\
6 & B & The fender was dented in an accident. \\
7 & B & She blushed with embarrassment. \\
8 & B & She folded the towels and sheets. \\
9 & B & The park was filled with flowering shrubs and trees. \\
10 & B & The home team was ahead by three goals. \\
1 & C & The man received holy communion on Ash Wednesday. \\
2 & C & Use a whisk to beat the egg whites. \\
3 & C & She threaded the needle, then sewed the button on. \\
4 & C & She felt dizzy and nauseated and then fainted. \\
5 & C & The company established a branch in Italy. \\
6 & C & He checked the tire pressure with a gauge. \\
7 & C & The child started whining because he was frustrated. \\
8 & C & The man shaved in front of the mirror over the sink. \\
9 & C & These perennials bloom each summer. \\
10 & C & The team members must buy their own cleats but not their jerseys. \\
\hline
\end{tabular}

\section{ACKNOWLEDGMENTS}

This research was supported by Grant DC00257 from the National Institute for Deafness and Other Communicative Disorders. The authors thank J. Prosperine and M. Pearse for help locating participants, Fr. M. Brodeur of St. Anthony's Church, and all of the participants. Thanks are also extended to L. Gunnin for making the sentence duration measurements and to K. Aoyama, S. Imai, P. Golato, L. Legault, K. Tsukada, and three anonymous reviewers for comments on earlier versions of this article.

\section{NOTES}

1. The participants subsequently took part in a word production experiment and experiments examining the perception of consonants and vowels. These experiments will be reported elsewhere. 
Flege et al.: Assessing bilingual dominance

2. AOA did not interact significantly with L1 use in any of the ANOVAs just reported, AOA: $F(1,68)=0.9, p>.10$, years of education in Canada: $F(1,68)=1.78, p>$ .10 ; LOR in Canada: $F(1,68)=0.0, p>.10$.

3. Of the 72 bilinguals tested, 27 had received 4 or fewer years of education in Italy and 17 had received a total of 8 or fewer years of education in Italy and Canada combined.

4. This participant had received no education in Italy and had the lowest verbal and written self-rating ratios of any of the 18 early low participants. His average selfestimated percentage of use of Italian (5\%) was the median for his group.

5. Bahrick et al. (1994) determined bilingual dominance by comparing the scores obtained in matched L1 and L2 performance tests.

\section{REFERENCES}

Bahrick, H., Hall, L., Goggin, J., Bahrick, L., \& Berger, S. (1994). Fifty years of language maintenance and language dominance in bilingual Hispanic immigrants. Journal of Experimental Psychology: General, 123, 264-283.

Bialystok, E., \& Miller, B. (1998). The problem of age in second-language acquisition: Influences from langauge, structure, and task. Bilingualism: Language and Cognition, 2, 127-145.

Chincotta, D., \& Underwood, G. (1999). Non-temporal determinants of bilingual memory capacity. Bilingualism: Language and Cognition, 1, 117-130.

Cromdal, J. (1999). Childhood bilingualism and metalinguistic skills: Analysis and control in young Swedish-English bilinguals. Applied Psycholinguistics, 20, 1-20.

Cucchiarini, C., Strik, H., \& Boves, L. (2000), Quantitative assessment of second language learners' fluency by means of automatic speech recognition technology, Journal of the Acoustical Society of America, 107, 989-999.

Cutler, A., Mehler, J., Norris, D., \& Segui, J. (1989). Limits on bilingualism. Nature, 340, 229-230.

Cutler, A., Mehler, J., Norris, D., \& Segui, J. (1992). The monolingual nature of speech segmentation by bilinguals. Cognitive Psychology, 24, 381-410.

de Bot, K. (1992). A bilingual's production model: Levelt's speaking model adapted. Applied Linguistics, 13, 1-24.

DeKeyser, R. (2000). The robustness of critical period effects in second language acquisition. Studies in Second Language Acquisition, 22, 499-534.

Dornic, S. (1979). Information processing in bilinguals. Psychological Research, 40, 329-348.

Elsendoorn, B. (1984). Tolerances of durational properties in British English vowels. Unpublished doctoral dissertation, University of Utrecht, The Netherlands.

Favreau, M., \& Segalowitz, N. (1982). Second language reading in fluent bilinguals. Applied Psycholinguistics, 3, 329-341.

Favreau, M., \& Segalowitz, N. (1983). Automatic and controlled processes in the first- and secondlanguage reading of fluent bilinguals. Memory and Cognition, 11, 565-574.

Flege, J. (1995). Second-language speech learning: Theory, findings, and problems. In W. Strange (Ed.), Speech perception and linguistic experience: Issues in cross-linguistic research (pp. 229-273). Timonium, MD: York Press.

Flege, J., Frieda, A., \& Nozawa, T. (1997). Amount of native-language (L1) use affects the pronunciation of an L2. Journal of Phonetics, 25, 169-186.

Flege J., MacKay, I., \& Meador, D. (1999). Native Italian speakers' production and perception of English vowels. Journal of the Acoustical Society of America, 106, 2973-2987.

Flege, J., Munro, M., \& MacKay, I. (1995a). The effect of age of second language learning on the production of English consonants. Speech Communication, 16, 1-26.

Flege, J., Munro, M., \& MacKay, I. (1995b). Factors affecting degree of perceived foreign accent in a second language. Journal of the Acoustic Society of America, 97, 3125-3134.

Flege, J., Schmidt, A., \& Wharton, G. (1996). Age affects rate-dependent processing of stops in a second language. Phonetica, 53, 143-161. 
Applied Psycholinguistics 23:4

Flege et al.: Assessing bilingual dominance

Flege, J., Yeni-Komshian, G., \& Liu, S. (1999). Age constraints on second language learning. Journal of Memory and Language, 41, 78-104.

Golato, P. (1998). Syllabification processes among French-English bilinguals: A further study of the limits of bilingualism. Unpublished doctoral dissertation, University of Texas-Austin.

Goggin, J., Estrada, P., \& Villarreal, R. (1994). Picture-naming agreement in monolinguals and bilinguals. Applied Psycholinguistics, 15, 177-194.

Green, D. (1986). Control, activation, and resource: A framework and a model for the control of speech in bilinguals. Brain and Language, 27, 210-223.

Grenier, G. (1984). Shifts to English as usual language by Americans of Spanish mother tongue. Social Science Quarterly, 62, 537-550.

Grosjean, F. (1982). Life with two languages. Cambridge, MA: Harvard University Press.

Grosjean, F, (1997). The bilingual individual. Interpreting, 2, 163-187.

Grosjean, F. (1998). Studying bilinguals: Methodological and conceptual issues. Bilingualism: Language and Cognition, 1, 117-130.

Guillelmon, D., \& Grosjean, F. (2001). The gender marking effect in spoken word recognition. Memory and Cognition, 29, 503-511.

Guion, S., Flege, J., Liu, H., \& Yeni-Komshian, G. (2000). The relation between sentence duration and the age of second language learning. Applied Psycholinguistics, 21, 205-228.

Guion, S. Flege, J., \& Loftin, J. (2000). The effect of L1 use on pronunciation in Quichua-Spanish bilinguals. Journal of Phonetics, 28, 27-42.

Hazan, V., \& Boulakia, G. (1993). Perception and production of a voicing contrast by FrenchEnglish bilinguals. Language and Speech, 36, 17-38.

Jia, G., \& Aaronson, D. (1999). Age differences in second language acquisition: The dominant language switch and maintenance hypothesis. In A. Greenhill, H. Littlefield, \& C. Tano (Eds.), Proceedings of the 23rd Annual Boston University Conference on Language Development (pp. 301-312). Somerville, MA: Cascadilla Press.

Kearns, R. (1994). Prelexical speech processing by monolinguals and bilinguals. Unpublished doctoral dissertation, Cambridge University.

Kohnert, K., Bates, E., \& Hernandez, A. (1999). Balancing bilinguals: Lexical-semantic production and cognitive processing in children learning Spanish and English. Journal of Speech, Language, and Hearing Research, 42, 1400-1413.

Lambert, W. (1955). Measurement of the linguistic dominance of bilinguals. Journals of Abnormal Social Psychology, 50, 197-200.

Lambert, W. (1990). Persistent issues in bilingualism. In B. Harley, P. Allen, J. Cummins, \& M. Swain (Eds.), The development of second language proficiency (pp. 201-218). Cambridge: Cambridge Unversity Press.

Lambert, W., Havelka, J., \& Gardner, R. (1959). Linguistic manifestations of bilingualism. American Journal of Psychology, 72, 77-82.

Lemmon, C., \& Goggin, J. (1989). The measurement of bilingualism and its relationship to cognitive ability. Applied Psycholinguistics, 10, 133-155.

Little, R., \& Rubin, D. (1987). Statistical analysis with missing data. New York: Wiley.

Liu, H., Bates, E., \& Li, P. (1992). Sentence interpretation in bilingual speakers of English and Chinese. Applied Psycholinguistics, 13, 451-484.

MacKay, I., Meador, D., \& Flege, J. E. (2001). The identification of English consonants by native speakers of Italian. Phonetica, 58, 103-125.

Macnamara, J. (1969). How can one measure the extent of a person's bilingual proficiency? In L. Kelly (Ed.), Description and measurement of bilingualism: An international seminar, University of Moncton, June 6-14, 1967 (pp. 80-97). Toronto: University of Toronto Press.

Măgiste, E. (1979). Recall of abstract and concrete sentences in bilinguals. Scandinavian Journal of Psychology, 20, 179-185.

Mägiste, E. (1992). Second language learning in elementary and high school students. European Journal of Cognitive Psychology, 4, 355-365.

Meador, D., Flege, J., \& MacKay, I. (2000). Factors affecting the recognition of words in a second language. Bilingualism: Language and Cognition, 3, 55-67.

Meuter, R., \& Allport, A. (1999). Bilingual language switching in naming: Asymmetrical costs of language selection. Journal of Memory and Language, 40, 25-40. 
Applied Psycholinguistics 23:4

Flege et al.: Assessing bilingual dominance

Munro, M. (1999). The role of speaking rate in the perception of L2 speech. Journal of the Acoustical Society of America, 105, 1032(A).

Munro, M., Flege, J., \& MacKay, I. (1996). The effect of age of second-language learning on the production of English vowels. Applied Psycholinguistics, 17, 313-334.

Ooyen, B., Cutler, A., \& Bertinetto, P. M. (1993). Click detection in Italian and English. Proceedings of Eurospeech '93 (Vol. 1, pp. 671-674).

Peal, E., \& Lambert, W. (1962). The relation of bilingualism to intelligence. Psychological Monographs, 76, 1-23.

Pennington, M. (1992). Discourse factors related to L2 phonological proficiency: An exploratory study. In J. Leather \& A. James (Eds.), Proceedings of the 1992 Amsterdam Symposium on the Acquisition of Second-Language Speech (pp. 137-155). University of Amsterdam.

Piske, T., Flege, J., MacKay, I., \& Meador, D. (2002). The production of English vowels by fluent early and late Italian-English bilinguals. Phonetica, 59, 49-71.

Piske, T., MacKay, I., \& Flege, J. (2001). Factors affecting degree of foreign accent in an L2: A review. Journal of Phonetics, 29, 191-215.

Raupach, M. (1980). Temporal variables in first and second language speech production. In H. Dechert \& M. Raupach (Eds.), Temporal variables in speech: Studies in honour of Frieda Goldman-Eisler (pp. 263-270). The Hague: Mouton.

Riggenbach, H. (1991). Toward an understanding of fluency: A microanalysis of nonnative speaker conversations. Discourse Processes, 14, 423-441.

Roberts, P., MacKay, I., \& Flege, J. (2002). Lexical and syntactic errors in translation by ItalianEnglish bilinguals. Brain and Cognition, 48, 513-516.

Talamas, A., Kroll, J., \& Dufour, R. (1999). From form to meaning: Stages in the acquisition of second-language vocabulary. Bilingualism: Language and Cognition, 2, 45-58.

Tamamaki, K. (1993). Language dominance in bilinguals' arithmetic operations according to their language use. Language Learning, 43, 239-262.

Yeni-Komshian, G., Flege, J., \& Liu, S. (2000). Pronunciation proficiency in the first and second languages of Korean-English bilinguals. Bilingualism: Language and Cognition, 3, 131150. 